\title{
Quickly Building Students' Confidence in their Fabrication Abilities
}

\section{Citation}

Faas, Daniela, and Daniel D. Frey. 2013. "Quickly Building Students' Confidence in their Fabrication Abilities." In the Proceedings of the American Society for Engineering Education (ASEE13), Atlanta, GA, June 23-26, 2013: ASEE-5823.

\section{Published Version}

https://www.asee.org/public/conferences/20/papers/5823/view

\section{Permanent link}

http://nrs.harvard.edu/urn-3:HUL.InstRepos:25586348

\section{Terms of Use}

This article was downloaded from Harvard University's DASH repository, and is made available under the terms and conditions applicable to Other Posted Material, as set forth at http:// nrs.harvard.edu/urn-3:HUL.InstRepos:dash.current.terms-of-use\#LAA

\section{Share Your Story}

The Harvard community has made this article openly available.

Please share how this access benefits you. Submit a story.

Accessibility 


\title{
Quickly Building Students' Confidence in their Fabrication
} Abilities

\begin{abstract}
Undergraduate mechanical engineering education usually places a high priority on design experience. Such courses serve to enhance student interest in engineering, improve retention, and improve results in later courses. A challenge to implementing early design experiences in engineering programs is the readiness of the student population for hands-on design work. One of the main obstacles the students face is the lack of fabrication experience. This typically leads students to begin work too late. This has been referred to as "time scallop"- as deadlines are approached, effort levels rise rapidly and fall back to low levels repeatedly. A problem motivating this paper is that students seemed hesitant to use machine tools despite previous introductory training including mills, lathes, saws, sheet metal cutting and bending. In this course, each student is expected to conceive, design, build, and operate a robot to carry out a specified set of tasks. This paper describes an activity that allows students to quickly build and test a robot within a 3-hour time frame. This robot, called "Mini-Me" serves most students as a starting point to build a more complex machine later on. Surveys indicate the activity builds students' confidence in their fabrication skills and that the gains are largest for female students. This work shows the benefit of giving students smaller subtasks to reduce anxiety about not having adequate skills to design and build a robot. This activity has enabled students to extract key concepts and the students felt more confident that they could complete a more complex robot. Overall, student's self-reported knowledge of servos, motors and using manufacturing equipment increased based on survey results. The activity described in this paper has had a large impact on overall manufacturing confidence and course outcome for students.
\end{abstract}

\section{Introduction}

Undergraduate mechanical engineering education usually places a high priority on design experience. This is partly driven by the requirements the Accreditation Board for Engineering and Technology (ABET) sets for engineering degrees ${ }^{1}$. ABET criteria (a) through (k) include design explicitly, especially through criteria (c) and (b). The ABET criteria also implicitly include design through requirements for teamwork, ethics, social context, and other broad considerations. The need to teach design has traditionally been addressed in Capstone courses. There is a trend to introduce design earlier in the curriculum such as through first-year introduction to engineering subjects or through required design "cornerstone" subjects"

A difficulty frequently observed in design projects is that students begin work too late. This has been referred to as "time scallop" -- as deadlines are approached, effort levels rise rapidly and fall back to low levels repeatedly ${ }^{2}$. A challenge to implementing early design experiences in engineering programs is the readiness of the student population for hands-on design work. Few students have been exposed to manufacturing equipment in high school or at home and therefore might feel frustrated and intimidated by courses that depend on manufacturing in the term projects. As one example, this paper will discuss a course on design at Massachusetts Institute of Technology (MIT) entitled 2.007: Design and Manufacturing I -- a sophomore level subject in Mechanical Engineering. For most students in that department, 2.007 represents their first opportunity to design and build a functioning machine. 
In the course 2.007, each student is expected to conceive, design, build, and operate a robot to carry out a specified set of tasks. Since there are no prerequisites to the course related to manufacturing or fabrication, 2.007 must introduce students to a wide range of processes that enable them to create useful machines including mills, lathes, saws, sheet metal cutting and bending, and so on. Many students do not feel confident about their fabrication skills when entering the course. Possibly due to this lack of confidence, many students delay prototype fabrication, which can negatively impact their design process ${ }^{3}$.

This paper describes a manufacturing exercise intended to help students overcome their concerns about fabrication skills and get them engaged in building earlier in the course. In the second week of 2.007, students build a simple robot over a period of about two hours. We chose to name the exercise "Mini-Me" because the resulting robot is among the smallest ones students ever make in this course. The following section describes the course goals and the tools provided to the students. The emphasis is on the main challenges of the course and the ways that a simple design activity helps to build confidence. Section 6 describes the Mini-Me manufacturing project and section 7 explains the impact of the project through presentation of survey data.

\section{Background}

There is a large and growing body of evidence that early project-based experiences (such as firstyear, cornerstone courses) are benefitting engineering students. They serve to enhance student interest in engineering, improve retention, and improve results in later courses ${ }^{2-18}$; that evidence is reviewed now. Assessment and outcomes research has been done more vigorously in recent years (see ${ }^{19}$ for a comprehensive survey), and there have been many studies of design per se (e.g. $\left.{ }^{20},{ }^{21}\right)$, and there are some assessment data on the impact of cornerstone project and design courses.

Olds and Miller" reported that "average" engineering students at the Colorado School of Mines (CSM) recruited into a pilot integrated curriculum that was intended to allow students "to discover and explore important connections among the humanities, physical and social sciences, and engineering subjects they studied in their first year at CSM" showed a 9\% increase in the 5year graduation rate, with much of the benefit being attributed to mentoring by senior faculty and the development of a sense of community. Richardson and Dantzler ${ }^{22}$ noted that the retention rates of students at the University of Alabama who take engineering courses in their first-year have improved as much as $16 \%$. Similarly, improvements in retention rates-especially among women and underrepresented minorities - attributable to building a sense of community among first-year students and mentoring by senior faculty has also been reported by Texas A \& $\mathrm{M}^{23}$ and the University of Florida ${ }^{24}$. Similar results are reported by the Gateway coalition of eight schools (Columbia, Cooper, Drexel, NJIT, Ohio State, Polytechnic Institute of NYU, South Carolina, USC) for second year retention rates of engineering students who in their first year have taken an integrated science program and a project-based course, with second year retention rates compared with national rates are $86 \%$ to $67 \%$ for minority students, $90 \%$ to $88 \%$ for women students, and $86 \%$ to $70 \%$ for all students ${ }^{25}$.

Fromm, director of the Gateway coalition, has estimated that their "project-based cornerstone course played a significant role in attaining the results" cited above ${ }^{26}$. While design courses were 
not specifically part of all curriculum changes and assessments, some sort of projects were generally included. Knight, Carlson and Sullivan studied the impact of the First-Year Engineering Project (FYEP) course at the University of Colorado at Boulder (CU) ${ }^{27}$. The CU course included "practical considerations of the design process, experimental testing and analysis, project management, oral and written communication, and working in multidisciplinary teams" - in other words, all of the elements of a first-year design course ${ }^{28}$ Retention gains ranging from $3 \%$ to $54 \%$ were reported at CU, with the largest being among women (27\%), African-American (36\%) and Latino (54\%) students. The smallest gains were among students of Asian descent (3\%). Similarly, at Carnegie Mellon University, where first-year courses are introductions to the disciplines that typically have several team-based project components to them and thus do have significant design content, such courses have had a significant impact on retention in the engineering program ${ }^{29}$. First-year retention rates went from about $80 \%$ to about $97 \%$ since the introduction of team-based project courses. While all of this gain cannot be solely attributed to these courses, they reportedly have provided a better basis for students to make choices of disciplines, gain valuable engineering experience, and gain an appreciation for the math and science courses they are taking as pre- and co-requisites to their engineering courses ${ }^{30}$. Note that this inference is similar to that drawn for the Gateway coalition experience ${ }^{26}$.

In short, while there is no definitive data specific to design courses, and while there are different views of the proper metric for assessing retention (e.g., see the discussion in ${ }^{31}$ ), there seem to be enough data to support the thesis that a design course or something that contains many of its elements - including projects, teams, written and oral communication - can produce positive changes in engineering student retention rates.

In terms of other measures of potential benefits of first-year design courses, little data are available. Purdue's EPICS program reports that students regarded teamwork, communication and time management and/or organization as "the three most valuable things . . . learned" from having taken the EPICS course ${ }^{30}$. The skills acquired here are the "soft" skills that ABET's EC 2000 is trying to promote. These results are quite consistent with — and supportive of - the anecdotal data heard from most teachers of such courses.

\section{Course Goals}

The course goals of Design and Manufacturing I are that students, after completing the course, will be able to:

1. Generate, analyze, and refine the design of electro-mechanical devices making use of physics, mathematics, and engineering principles.

2. Describe, analyze and select common machine elements including fasteners, joints, springs, bearings, gearing, motors, pneumatics, clutches, couplings, belts, chains, and shafts.

3. Apply experimentation and data analytic principles relevant to mechanical design.

4. Communicate a design and its analysis (written, oral, and graphical forms).

5. Develop basic machining and fabrication skills.

These topics are introduced during twice-weekly lectures and during weekly lab sessions. The lecture portion is used to introduce new material, to amplify with examples, to do interactive exercises, and to provide feedback on homework assignments and exams. The lab sessions are a mix of fabrication, electronics, programming, experimentation, peer group meetings, and oral 
reports. They are described in a set of eleven milestone documents describing the activities, deliverables, and expectations for each week. Communication is also a critical component to this course. Students are required to keep a lab notebook in order explain their designs, the methods used, and the underlying assumptions.

\section{Tools provided to Students}

Typically, 130-180 students are enrolled in the spring term. Each student is given a supply kit with hand tools, calipers, various metal, plastic and wood stocks as well as a variety of electromechanical devices. Several machine tools and other hand tools are provided for the students. Each student is given a supply kit with over 40 items at the beginning of the semester. The electronic and electro-mechanical components of the supply kit issued to the students include various electro-mechanical devices such as continuous rotation servos and a custom Arduino Nano carrier board (designed at MIT). Because of the amount and variety of components supplied to each student, corporate sponsorship is critical to offset the expenses of this course.

The students are given access to manufacturing equipment for use in the construction of their machines in the Pappalardo Lab. This course requires students to have a hands-on experience with tools such as drill presses, saws, milling machines, and lathes in order to build their robot (Fig. 1). In their kits, hand tools such as hammers, scissors, screwdrivers and wrenches are provided to each student to manufacture their designs.

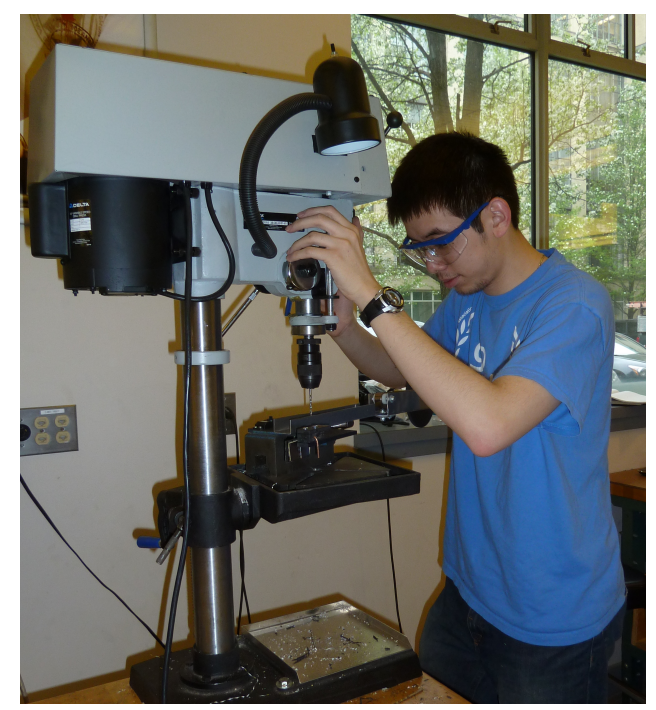

Figure 1: Student working at table-top drill during 2.007

More advanced manufacturing equipment such as CNC machining and water jetting is directed by the Pappalardo staff. Once students have gained enough experience using the advanced manufacturing equipment, they are allowed to use them without direct supervision. 3D printing is also available to the students and they are given an allocation of $6 \mathrm{in}^{3}$ of material as part of their kit.

\section{Course Layout and Contest}

A major element of this course is the design of a robot to participate in a challenge that changes from year to year. For example, in 2011 the theme was Hacking (the practical jokes students 
pull around MIT and the students' robot were challenged to attempt tasks like placing a police car on the University of MIT dome (Fig. 2) and inflating a balloon under the Harvard University football field. The students' machines begin the competition in a starting zone on their respective side of the playing field. A 15 second autonomous period begins when the contest is triggered and the robots are under radio control in the subsequent 75 seconds.

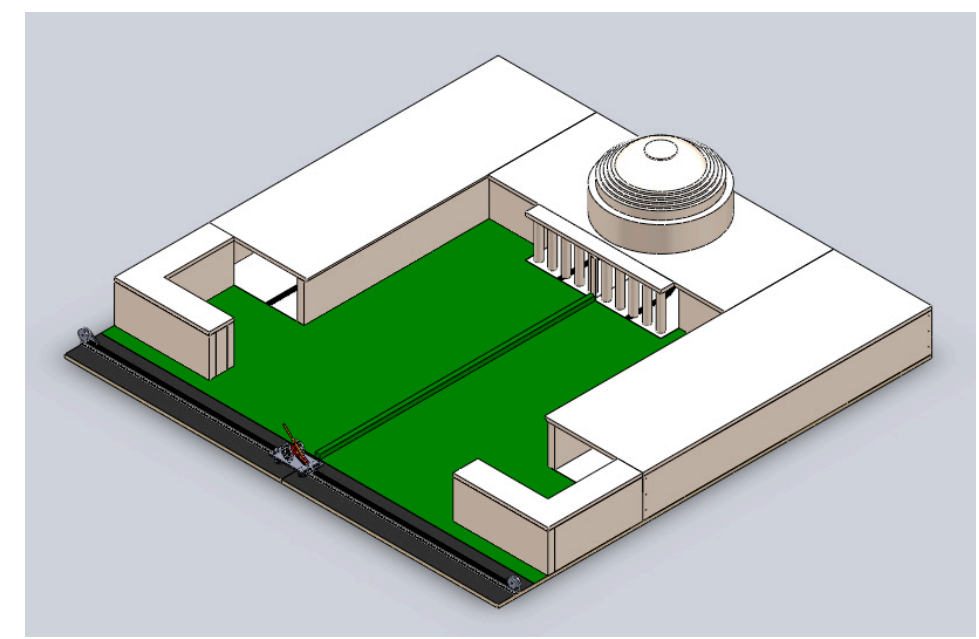

Figure 2: "Hackfest", competition table for 2011

The machine must be built only from kit materials and components, a specified list of approved items. The contest described here has no implications for grading. The course culminates in the second night of the contest: a single elimination tournament.

\section{Mini-Me Project}

Discussions among the faculty and teaching staff in 2.007: Design and Manufacturing I led to the conclusion that students are overly apprehensive about beginning to build prototypes. As a remedy, we proposed to add a short activity in the first couple weeks of the semester. We chose to develop the "Mini-me project" in which students built a small, radio controlled robot. The project was implemented with students for the first time in the spring of 2011 and has been used in 2012 and 2013.

The fabrication of the Mini-Me introduces the students to the main processes available to them for the robot contest later in the term. Mini-Me is built from a sheet of ABS plastic, 2 continuous rotation servos with servo wheels and a caster wheel. Nuts and bolts are used to fix the servos and caster wheel to the plastic body. A mechanical drawing of the Mini-Me chassis is shown in Fig. 3. In the process of building this robot, the students are taught how to use drill presses, band saw, and a heating element to enable easier bending of the ABS plastic in addition to hand tools such as screwdrivers. 


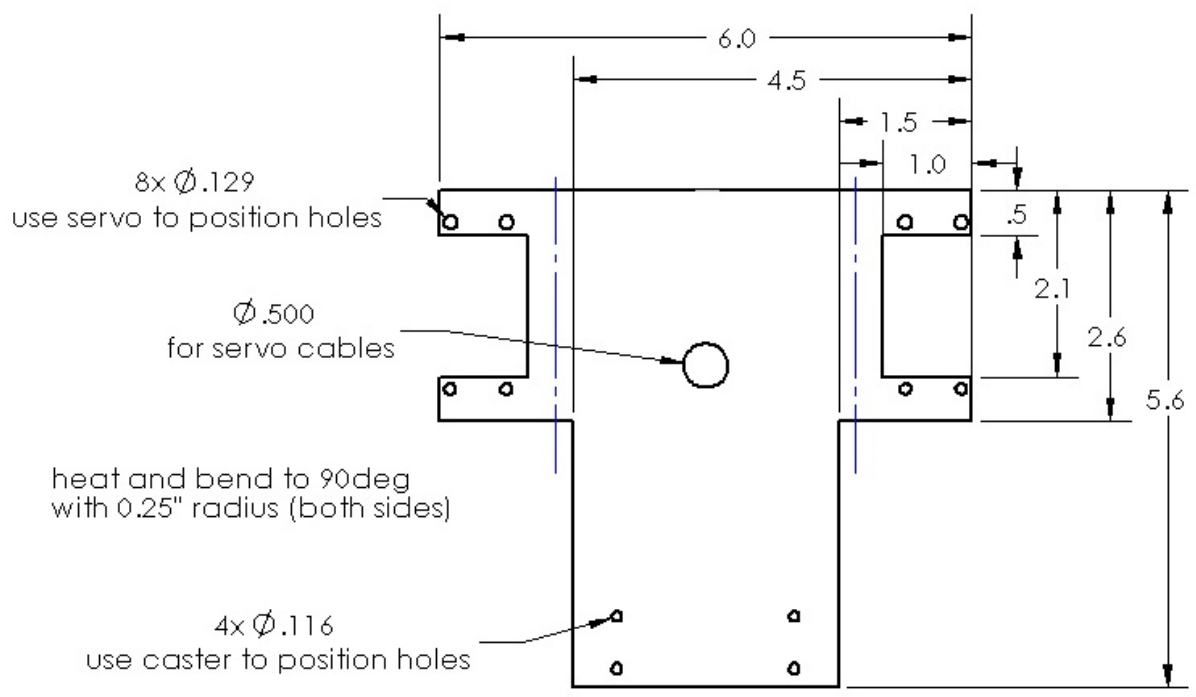

Figure 3: Mechanical Drawing of the Mini-Me chassis before bending (all units in inches)

The manufacturing process for Mini-Me is very simple and introduces students to basic fabrication concepts. The students were allowed to make modifications to the design and they were also told that used material would be replaced (so that their kits would not be diminished by the exercise). First, the ABS sheet is cut to the indicated dimensions using the tabletop band saw. Then, holes for the servo and caster wheel attachment were drilled. Students were introduced to the selection process for nuts and bolts at that time. Next, the cut ABS plastic was placed on a line-heating element and once the plastic was heated beyond its glass transition temperature, the ABS was bent by 90 degrees in two places to form two servo mounting features. Lastly, the servos and caster wheel were attached to the body (Fig. 4). Students could then plug in the servo wires into a radio controller (or else an Arduino carrier board as shown in Figure 4) and drive Mini-Me around.

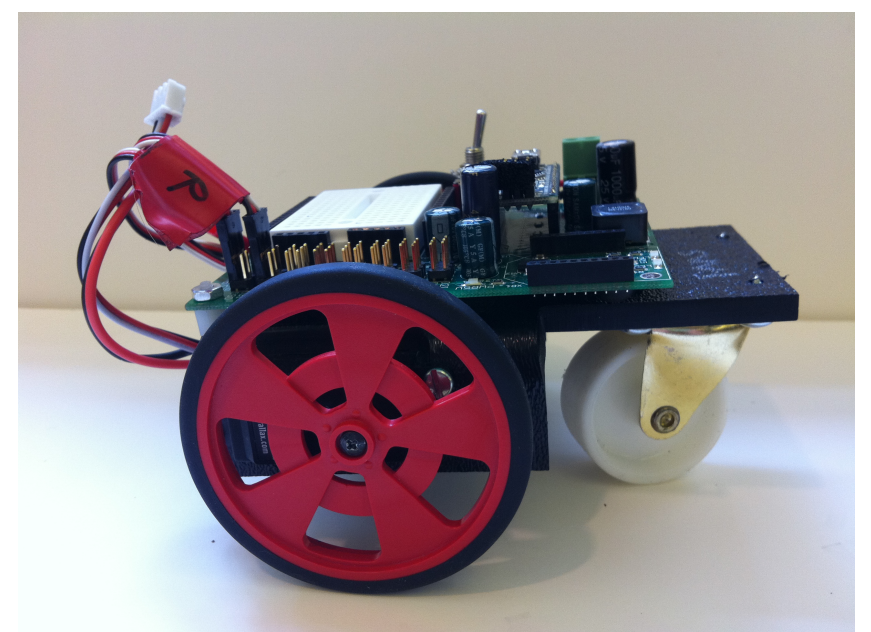

Figure 4: Finished Mini-Me with Arduino microcontroller board 
In developing the Mini-me project, some iterative refinements were required. In an early version of the design, the servo mounting features included pockets in the ABS sheet requiring either CNC milling or water-jet operations (Figure 5a). We decided to change the design to an open feature that could be made on the band saw (Figure 5b). The key issue is that the Pappalardo lab has several band saws that are readily available to the students with essentially no waiting. By contrast, the $\mathrm{CNC}$ mill and water jet machines require more wait time and more assistance by the lab staff. Therefore, the design change substantially reduced the build time, increase the autonomy of the students undertaking the project, and may have contributed to the observed benefits in self-confidence described in the next section entitled "survey results."

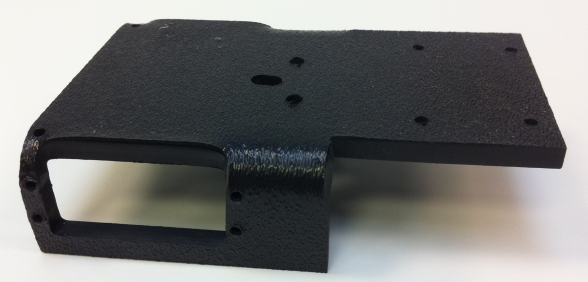

A)

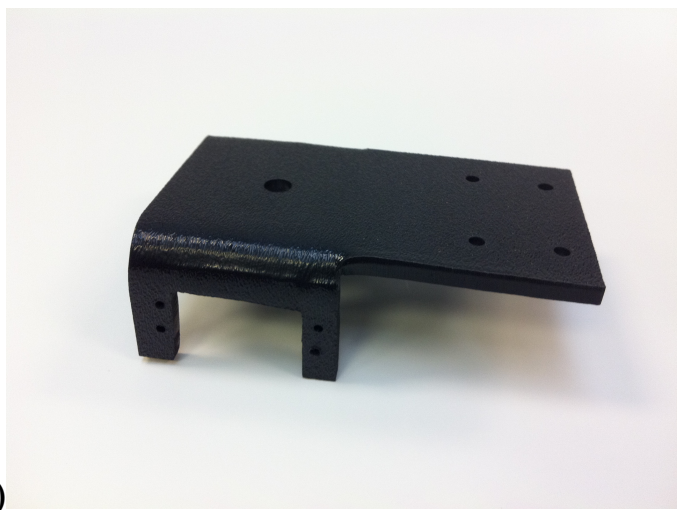

B) band saw

The cost of Mini-Me is very low compared the overall cost of the kits the students receive. The Mini-Me has a total cost of $\$ 75$ including radio receivers and other components such as batteries that are a shared resource for all 160 students. The Mini-Me itself costs around \$20, which includes the ABS sheet, servos, tires and caster swivels. However, all components besides the ABS sheet $(\sim 3)$ can be used for the final robot design. Because most components can be reused, the Mini-Me is cost-effective for this initial exercise and students are told that used materials will be replaced.

The experience in Spring 2011 indicated that Mini-Me could be completed by inexperienced students in two hours (on average) with minimal guidance. Even students with no prior manufacturing experience were able to complete the project within the four-hour lab time. Graduate students and instructors as well as the lab staff helped students if they had questions about any part of the manufacturing process. Instructors and teaching assistants also helped students with the radio controllers.

\section{Survey Results}

The survey was completed by 57 undergraduate students enrolled in 2.007 at MIT after having completed the course. The students were looking back on their abilities and confidence from a time "before" the course, but opinions were formed at a time "after" the course. The sample population featured 34 females and 23 males with ages ranging from 18 to 22 years of age (mean of 19.84 years). No compensation was provided to the participants and it was voluntary. The online survey could be completed in less than 10 minutes. 
The first question on the survey aimed to determine whether 2.007 improved sketching andfabrication abilities in students. The responses were evaluated from a scale of 1 to 5 , where 1 is novice and 5 is expert. Figure 5 shows the responses to sketching and making things before and after taking the course (with the error bars indicating the inter-quartile range).

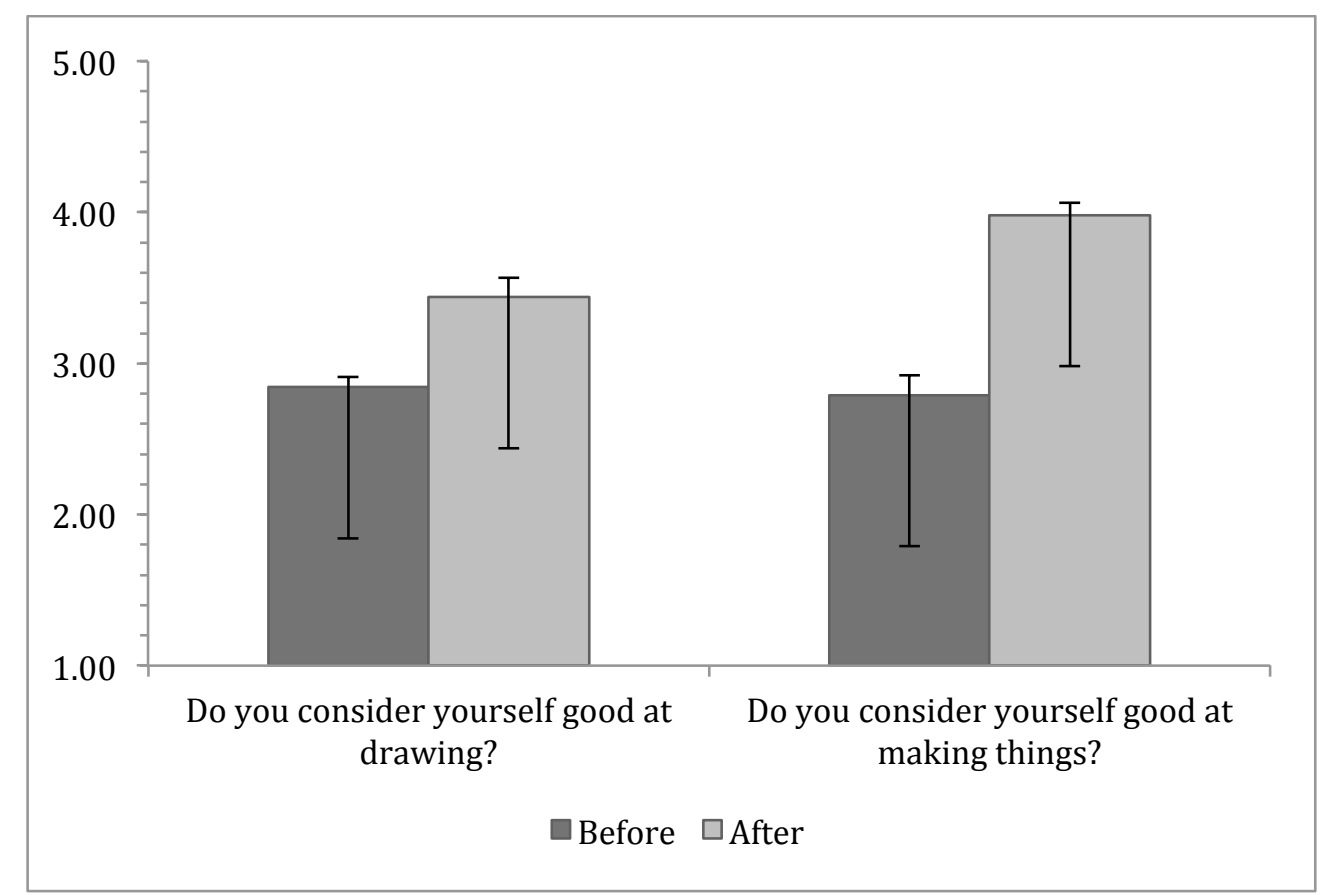

Figure 6: Before and after assessment of drawing and fabrication skills for 2.007 students. The bars indicate the average response and interquartile ranges are superposed.

Before taking the course, the drawing skills were evaluated at 2.84 (interquartile range, 2-4), while afterwards, the students felt that they were much better at drawings with a median 3.43 (interquartile range, 3-4). A one-way Analysis of Variance (ANOVA) showed that there is a (statistically) significant difference among the population means, $\mathrm{F}(1,112)=8.5, \mathrm{p}=0.004$. Even more drastically, students felt that they were much better after making things after taking the course. Prior to this course the students' rated their ability to make things at 2.79 (interquartile range, 2-4). This improved statistically significant after taking the course to 3.98 (interquartile range, $4-4), F(1,112)=50.22, p<0.001$, which is to be expected after a manufacturing intensive course.

Students were then asked which activities they felt were the most helpful throughout the duration of the course. Again, the responses were scaled from 1 to 5 , where 1 was the least helpful and 5 was very helpful. Unsurprisingly, the interactions with both instructors (4.28, interquartile range, 4-5) and machine shop personnel (4.61, interquartile range, 4-5) ranked the highest. The design notebooks (4.04, interquartile range, $4-5)$ were also highly regarded by students. The manufacturing tutorials (3.58 interquartile range, $4-5$ ) were 10 to 15 minutes introductions to several fabrication concepts led by the lab staff.

Next, the survey asked the students about Mini-Me. Again, answers were rating from 1 to 5 , with 5 being the highest rating possible. Students thought that they found Mini-Me to be easy to make 
and that they did not feel stressed while building Mini-Me. Confidence levels went up after students completed the activity. Students were highly satisfied with their Mini-Me and thought that the given 3-hour lab session was enough time to complete the project.

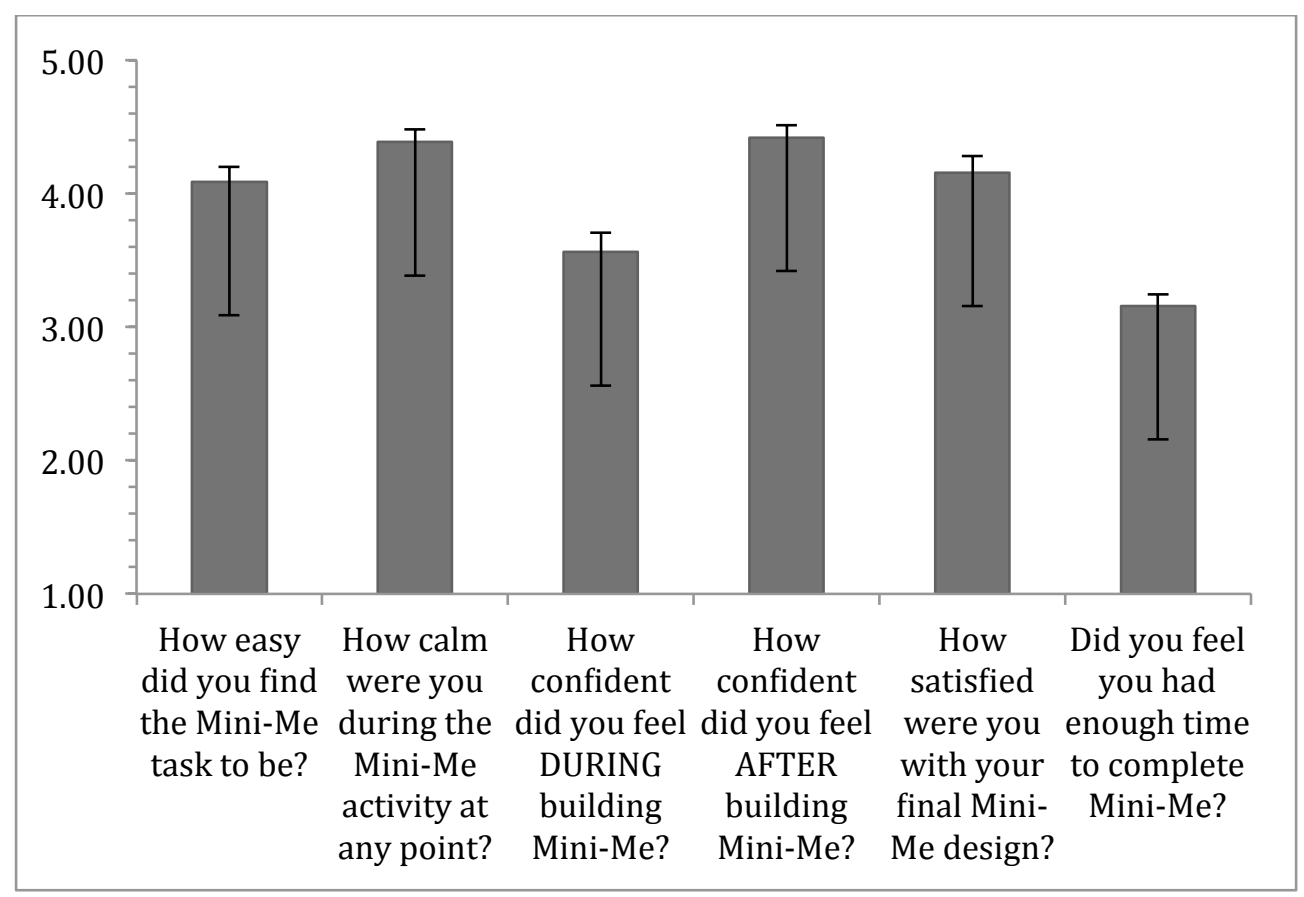

Figure 7: Student's evaluation of the Mini-Me activity

In addition to the Mini-Me activities, students were asked about their manufacturing confidence levels before and after completing Mini-Me. A confidence level of 1 indicated no or minimal prior familiarity or knowledge. A confidence level of 5 showed advanced knowledge and demonstrating a superior understanding and the ability to handle problems and materials encountered. The least improved tools were hand tools and the hand drill (Fig. 8). 


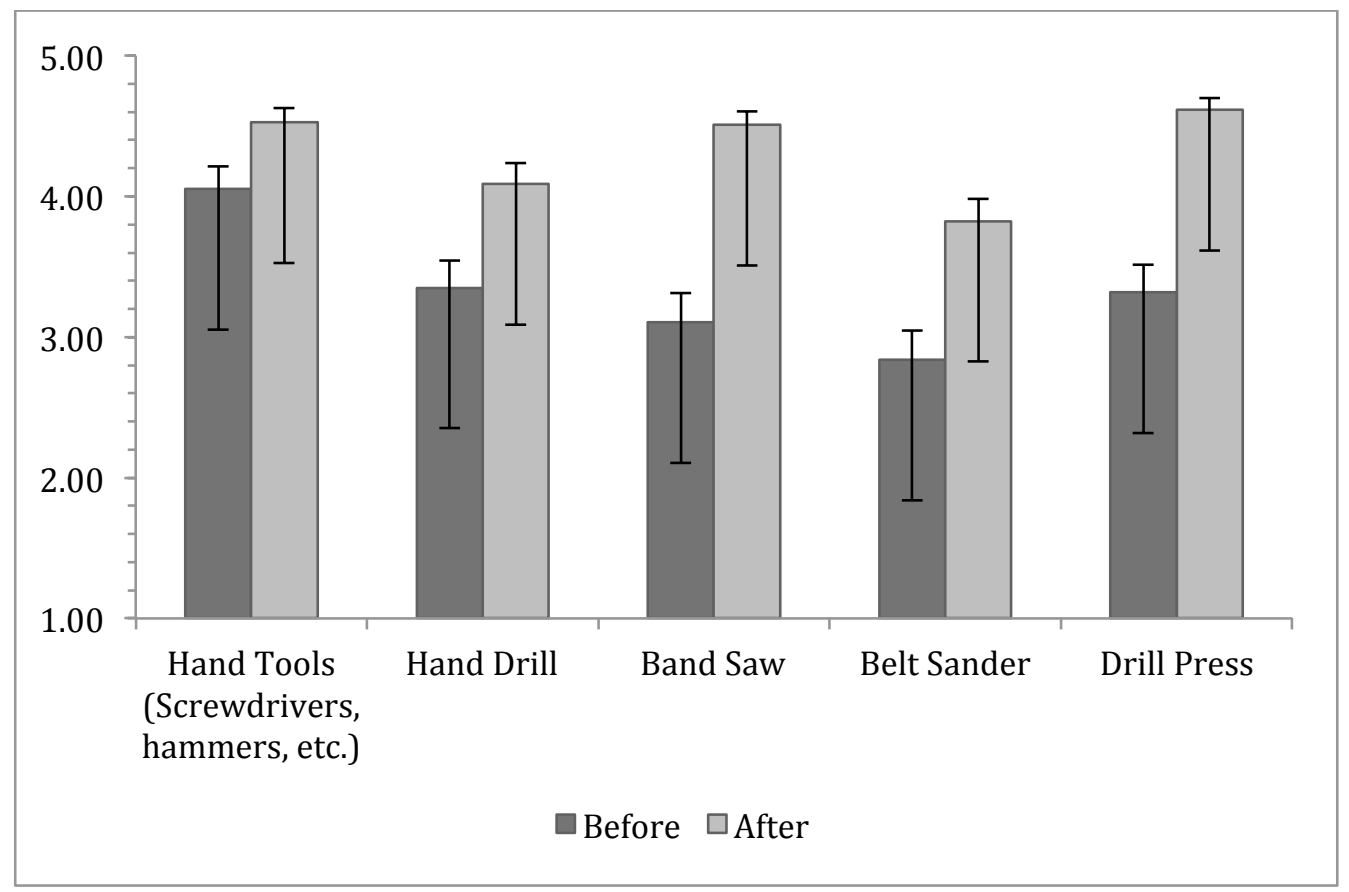

Figure 8: Student's confidence levels before constructing Mini-Me and after course
completion

The more advanced tools saw a significant improvement, particularly the band saw and the drill press. The belt sander was not needed to complete the Mini-Me, but some students chose to smooth the edges. The Mini-Me project was considered by students and faculty alike to be a great success. One student's comments were that she was "terrified" of the fabrication equipment prior to building Mini-Me. After the Mini-me exercise, she felt comfortable around the tabletop machinery and was excited to learn how to use the bigger machines. Overall, student's knowledge of servos, motors and using manufacturing equipment increased.

\section{Gender}

Substantial amount of research in engineering education is geared towards retention of female students in the engineering fields. While the Mini-Me activity was not geared towards any particular gender, the impact for the female students in the class was profound. Figure 10 shows the differences between male and female students and their levels confidence levels before the mini-me activity and after taking the course. Both groups reported similar confidences in drawing skills before taking the course, $\mathrm{F}(1,55)=0.94, \mathrm{p}=0.76$, and after taking the course, $\mathrm{F}$ $(1,55)=0.33, p=0.57$. Comparing the manufacturing confidences shows a significant differences between women and men in the class before completing the Mini-Me design activity, $\mathrm{F}(1,55)=13.84, \mathrm{p}<0.001$. The differences in building confidence seem to be reduced after completion of the course. The men and women reported a significantly smaller difference, $\mathrm{F}$ $(1,55)=3.97, \mathrm{p}=0.05$ after taking the course. 


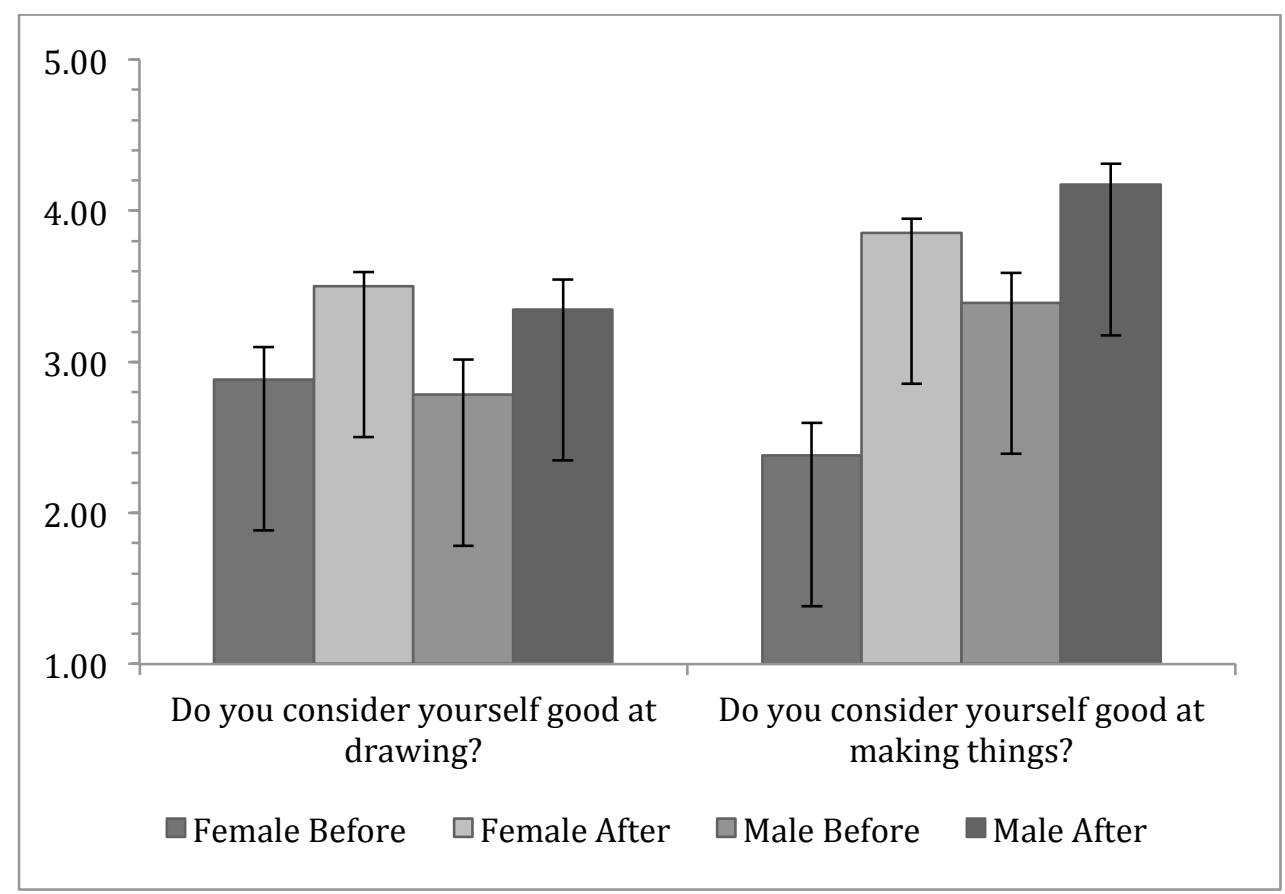

Figure 9: Improvements of building confidence in female students

Furthermore, there was no significant difference between men and women regardless of their reported building confidence when they reported their satisfaction with the Mini-Me project. There was a slight difference in how the women perceived the easiness of the task compared to the men in the class. The women thought the task to be slightly more difficult than their male peers. In addition, they felt slightly less calm and confident during the Mini-Me activity. Table 1 shows the $\mathrm{F}$ and $\mathrm{p}$ values for the results of the survey.

Table 1: $F$ and $p$ value during and after building Mini-Me between genders

\begin{tabular}{lcc}
\hline Survey Question & F (1, 55) & $\boldsymbol{P}$ \\
\hline How easy did you find the Mini-Me task to be? & 11.32 & $<0.001$ \\
How calm were you during the Mini-Me activity at any point? & 13.11 & $0<0.001$ \\
How confident did you feel DURING building Mini-Me? & 14.85 & $<0.001$ \\
How confident did you feel AFTER building Mini-Me? & 3.04 & 0.09 \\
How satisfied were you with your final Mini-Me design? & 1.87 & 0.18 \\
Did you feel you had enough time to complete Mini-Me? & 5.38 & 0.02 \\
\hline
\end{tabular}




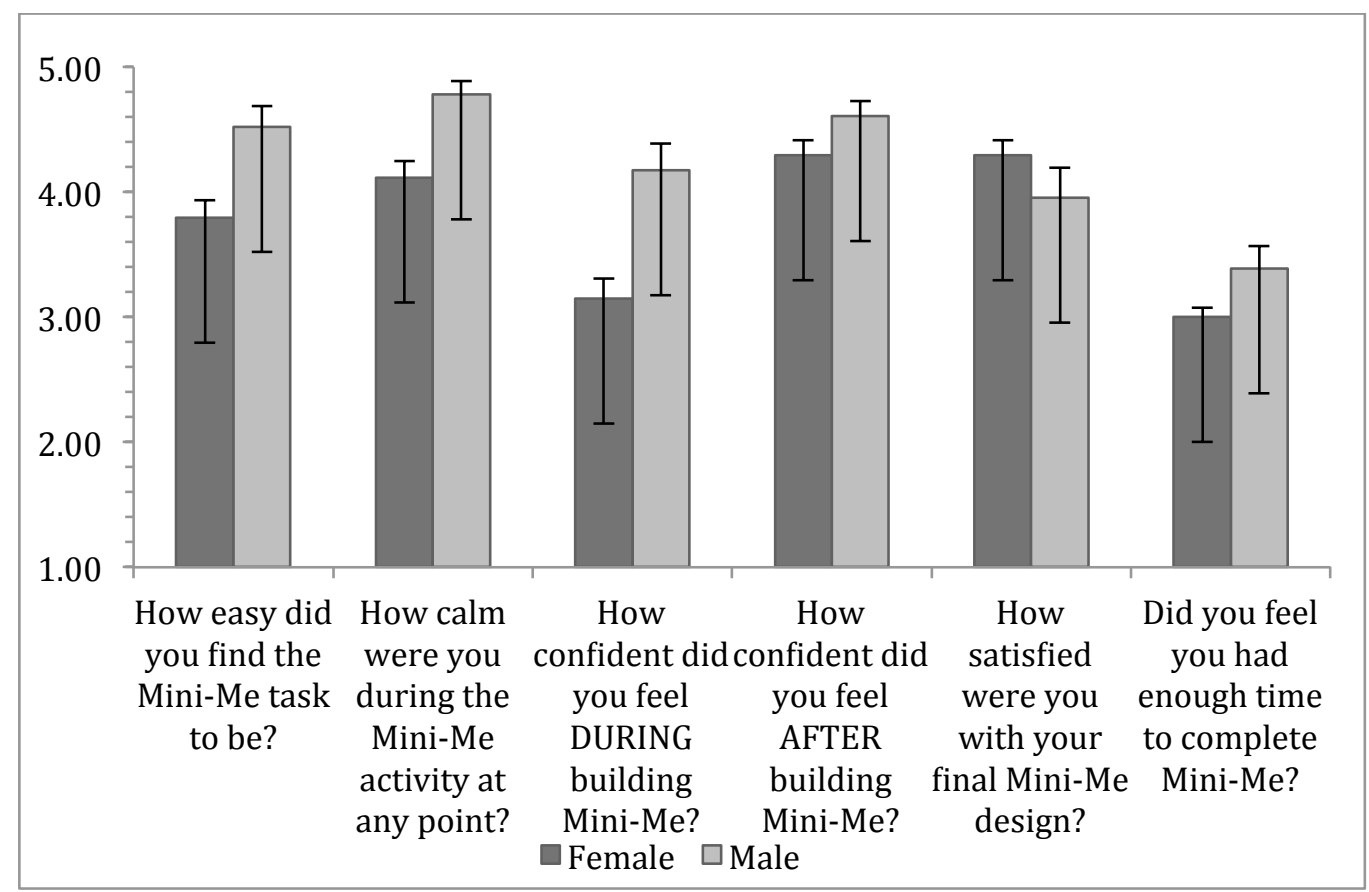

Figure 10: Confidence levels during and after building Mini-Me

The confidence level throughout the course improved for all students who participated in the survey, just as expected with a design course rooted in fabrication. Particularly female students reported improved confidence levels (see Fig. 12) in each tabletop manufacturing tool. The hand tools such as screwdrivers, and hammers had the least increase in confidence levels. While these results are not surprising, the effect of Mini-Me is still interesting because the effects are large and consistent for such a short exercise. The results of the survey instrument are not clear as they might have been had the students been asked to complete a pre- survey before the exercise. But, to the extent that students can reliably recall how confident they felt previously, the survey we actually administered should still provide reliable indications of efficacy. 


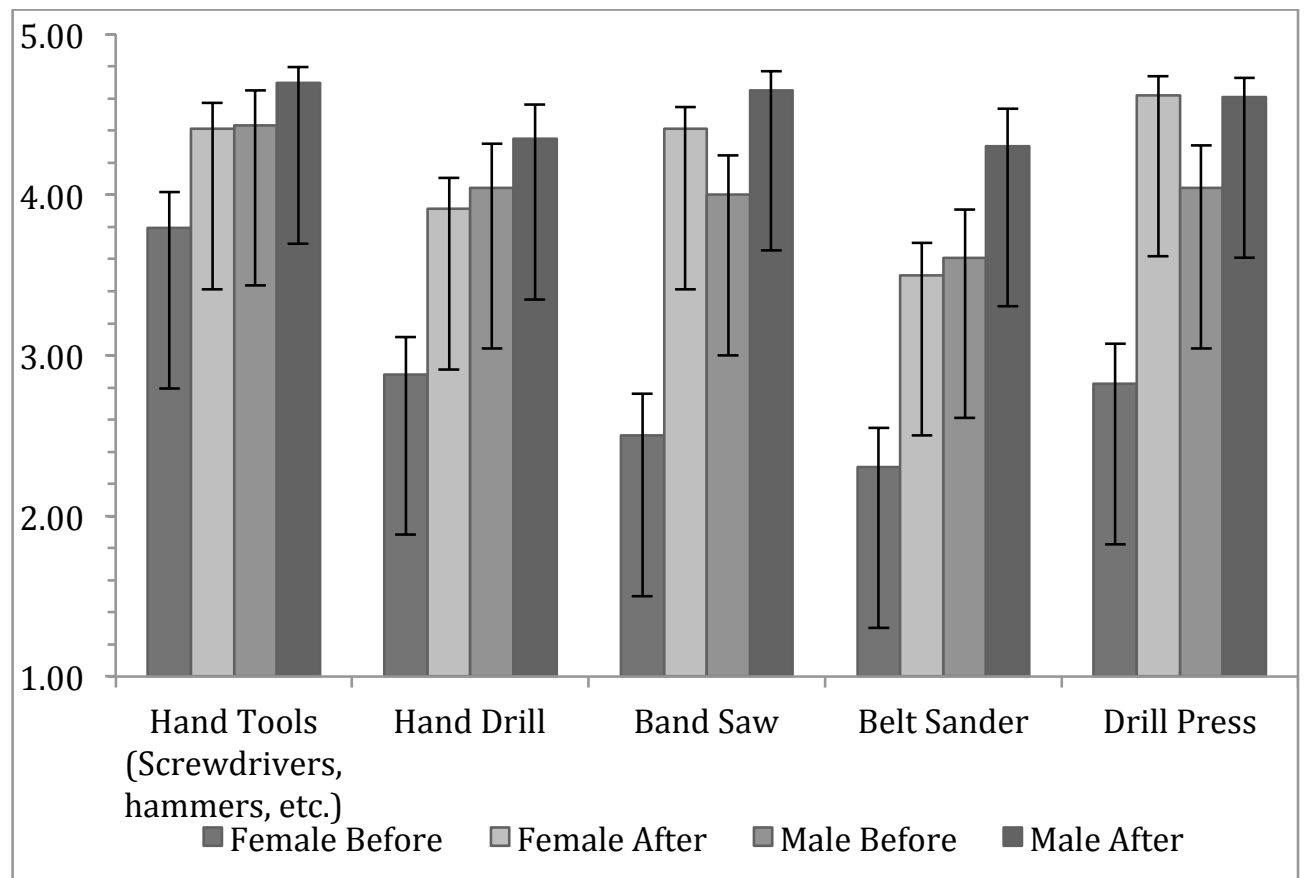

Figure 11: Fabrication tool confidence levels for men and women in the course before and after Mini-Me

Modifications to Mini-Me

Very few students chose to modify Mini-Me. Some students chose to manufacture Mini-Me from sheet metal (even though this option was not written down explicitly in the instructions). Some students chose to modify the dimensions of Mini-Me to build a larger body. Other comments from students ranged from wanting to learn sheet metal cutting and bending during Mini-Me to a more formalized introduction to control schemes for driving the robots.

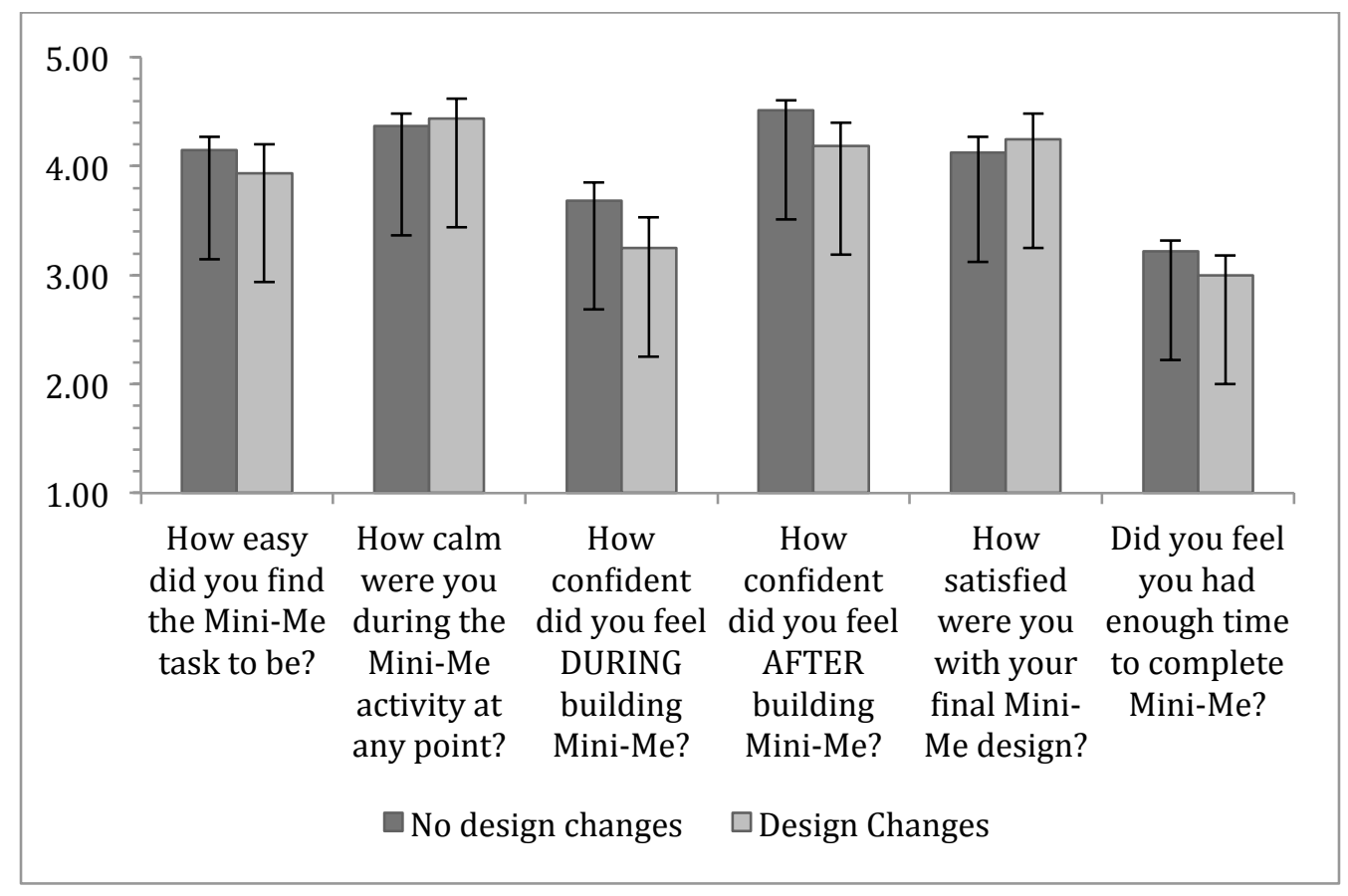




\section{Figure 12: Confidence levels in students with and without modifications to Mini-Me}

People that made changes did not report being significantly more confident than students that decided to stick with original design. None of the changes made by students involved fundamentally altering the manufacturing process. Overall, about $25 \%$ of the surveyed students chose to make changes to the design.

\section{Future Work}

The mini-me activity was well received by the students. Further manufacturing activities could include other simplified mechanisms such as graspers. The goal is to create a building activity that is not perceived as intimidating to students, even those with little prior knowledge. Yet the exercise should offer challenges appropriate for students that have had fabrication experience previously. This survey did not capture previous manufacturing knowledge and skills prior to taking 2.007. In particular, students that use manufacturing tools on a daily basis because of their involvement in clubs or other activates should be given the opportunity to mentor students with little or no prior experience. Creating a team atmosphere in an individual design task might reduce some of the stress that students feel in this class. Future studies should track time spent over the semester on machine and tools.

The students learn basic mechatronics concepts such as controlling motors, reading sensor input, and control system programming throughout the duration of the course. However, most of these concepts are introduced very late and might deter students from adoption of the microcontrollers in their robots. Mini-me currently only used radio controllers and introduced students to those controllers. If these basic mechatronics concepts can be introduced as a hands-on experience such as the Mini-Me, the hurdle of overcoming the fear of programming and electronics for Mechanical Engineering students can be substantially decreased. Because this course is intensive, not much time can be devoted to extending the Mini-Me project beyond 2 laboratory sessions.

\section{Conclusion}

The activity described in this paper has had a large impact on overall manufacturing confidence and competition outcome for students. 2.007: Design and Manufacturing I provides most students with their first machining and fabrication experience as well as an introduction to programming microcontrollers. The final robot and the competition is the highlight for many of the students' undergraduate experience at MIT. Mini-Me has had a large impact on overall course and has enabled students to be less afraid of manufacturing part of the course. In previous years, students were too afraid of the manufacturing equipment and the design process was too unfamiliar. Mini-Me was so successful because it interjected at a critical time point for students where they needed a stepping-stone in order to design their final robot. Previously, students did not start building until the second half of the semester.

Currently, no direct measures of student outcomes are observed. In the future, design notebooks will be collected and analyzed by a design committee. Additionally, students that did not complete the Mini-Me activity will be asked to complete a similar survey to gage their experience with building other electro-mechanical devices. Analysis and comparison of previous years might not be possible as the robot kits, CAD software, the contest and other factors have changed significantly. However, the level of design and fabrication could be assessed via contest 
footage and "donated" robots from previous years. The Mini-Me activity will used by a freshman introductory design course at Singapore University of Technology and Design (SUTD), where students will be asked to complete the survey.

Introducing students to manufacturing using simple robots can enable them to build more complex robots in 2.007 by building their confidence levels. Ideally, students would be more self-reliant and use less help from staff. Students would build sooner and more often and become more comfortable with the design process as they have a fully functional robot in Mini-Me early in the semester. Additionally, students would be more confident in their robots ability to compete and score points during the 2.007 competitions. In the future, Mini-Me will be introduced with a microcontroller programming assignment to give students a quick overview on how to implement simple servo controls with an Arduino Nano board. Ultimately, the goal of a fabrication activity is to broaden students' participation in manufacturing and to deepen students' understanding of design and manufacturing concepts. Students are able to better handle problems, machines, and materials encountered in other design courses and are looking forward to hands-on fabrication.

\section{Acknowledgements}

The authors would like to thank the 2.007 instructors, teaching fellows and teaching assistants. In addition, we would like to thank the Pappalardo staff for their continued support.

\section{References}

[1] Accreditation Board for Engineering and Technology. (2009, Criteria for Accrediting Engineering Programs: Effective for Evaluations During the 2010-11 Accreditation Cycle. Available: http://www.abet.org

[2] S. S. Moor and B. D. Drake, "Addressing Common Problems in Engineering Design Projects: A Project Management Approach," Journal of Engineering Education, vol. 90, pp. 389-395, 2001.

[3] J. D. Bransford, A. L. Brown, and R. R. Cocking, How People Learn: Brain, Mind, Experience, and School. Washington, DC: National Academy Press, 2000.

[4] J. L. Faust and D. R. Paulson, " Active Learning in the College Classroom," Journal on Excellence in College Teaching, vol. 9, pp. 3-24, 1998.

[5] R. R. Hake, "Interactive Engagement vs. Traditional Methods: A Six-thousand-student Survey of Mechanics Test Data for Introducing Physics Courses," American Journal of Physics, vol. 66, pp. 64-74, 1998.

[6] G. Marbach-Ad, 0. Seal, and P. Sokolove, "Student Attitudes and Recommendations on Active Learning," Journal of College Science Teaching, vol. 30, pp. 434-438, 2001.

[7] R. M. Felder and R. Brent, "Navigating the Bumpy Road to Student-centered Instruction," College Teaching, vol. 44, pp. 43-47, 1996.

[8] S. Butler, "Catalyzing Student Autonomy Through Action Research in a Problem-centered Learning Environment," Research in Science Education, vol. 29, pp. 127-140, 1999.

[9] B. M. Olds and R. L. Miller, "The Effect of a First-Year Integrated Engineering Curriculum on Graduation Rates and Student Satisfaction: A Longitudinal Study," Journal of Engineering Education, vol. 93, pp. 23-35, 2004.

[10] M. Hoit and M. Ohland, "The Impact of a Discipline-Based Introduction to Engineering Course on Improving Retention," Journal of Engineering Education, vol. 87, pp. 79-85, 1998.

[11] D. W. Knight, L. E. Carlson, and J. F. Sullivan, "Staying in Engineering: Impact of a Hands-On, TeamBased, First-Year Projects Course on Student Retention," in ASEE Annual Conference \& Exhibition, 2003. 
[12] L. G. Richards and S. Carlson-Skalak, "Faculty Reactions to Teaching Engineering Design to First year Students," Journal of Engineering Education, vol. 86, pp. 233-292, 1997.

[13] C. J. Atman, J. R. Chimka, K. M. Bursic, and H. L. Nachtman, "A Comparison of Freshman and Senior Engineering Design Processes," Design Studies, vol. 20, p. 1310152, 1999.

[14] R. S. Adams, P. Punnakanta, C. J. Atman, and C. Lewis, "Comparing Design Team SelfReports with Actual Performance: Cross-Validating Assessment Instruments," in ASEE Annual Conference \& Exhibition, 2002.

[15] A. M. Agogino and M. C. Linn, "Retaining Female Engineering Students; Will Early Design Experiences Help?," Viewpoint Editorial, NSF Directions, National Science Foundation, vol. 5, pp. 8-9, 1992.

[16] A. M. Agogino, C. Newman, M. Bauer, and J. Mankoff, "Perceptions of the Design Process: An Examination of Gendered Aspects of New Product Development," International Journal of Engineering Education, vol. 20, pp. 452-460, 2004.

[17] C. L. Dym, "Teaching Design to Freshmen: Style and Content," Journal of Engineering Education, vol. 83, pp. 303-310, 1994.

[18] C. Dym, A. Agogino, O. Eris, D. Frey, and L. Leifer, "Engineering Design Thinking, Teaching, and Learning," Journal of Engineering Education, vol. 94, pp. 103-120, 2005.

[19] K. N. Brown, C. A. McMahon, and J. H. Sims, "Features, aka The Semantics of a Formal Language on Manufacturing," Research in Engineering Design, vol. 7, pp. 151-172, 1995.

[20] A. Dong, A. W. Hill, and A. M. Agogino, "A Document Analysis Method for Characterizing Team-Based Design Outcomes," Journal of Mechanical Design, vol. 126, pp. 378-385, 2004.

[21] A. H. Hill, A. Dong, and A. M. Agogino, "Identifying Shared Understanding in Design using Document Analysis," in Proceedings of the 13th International Conference on Design Theory and Methodology, Pittsburgh, PA, 2001.

[22] J. Richardson and J. Dantzler, "Effect of a Freshman Engineering Program on Retention and Academic Performance," in 2002 Frontiers in Education Conference.

[23] S. Song, A. Dong, and A. M. Agogino, "Time Variation of Design "Story Telling" in Engineering Design Teams," in International Conference on Engineering Design (ICED 03), Stockholm, Sweden, 2003.

[24] E. Y.-L. Do, M. D. Gross, B. Neiman, and C. Zimring, "Intentions in and relations among design drawings," Design Studies, vol. 21, pp. 483-503, 2000.

[25] M. Schütze, P. Sachse, and A. Römer, "Support Value of Sketching in The Design Process," Research in Engineering Design, vol. 14, pp. 89-97, 2003.

[26] D. G. Ullman, S. Wood, and D. Craig, "The Importance of Drawing in the Mechanical Design Process," Computers \& Graphics, vol. 14, pp. 263-274, 1990.

[27] S. Song and A. M. Agogino, "An Analysis of Designers' Sketching Activities in New Product Design Teams," in Proceedings of the ASME Design Theory and Methodology Conference, Salt Lake City, Utah, 2004.

[28] J. W. Dally and G. M. Zhang, "A Freshman Engineering Design Course," Journal of Engineering Education, vol. 83, pp. 83-91, 1994.

[29] M. C. Yang, "Concept Generation and Sketching: Correlations with Design Outcome," in 2003 ASME Design Engineering Technical Conferences, Chicago, IL, 2003.

[30] J. Shah, N. Vargas-Hernandez, and S. Smith, "Metrics for Measuring Ideation Effectiveness," Design Studies, vol. 24, pp. 111-134, 2003.

[31] C. P. Neck, M. L. Connerley, and C. C. Manz, "Toward a Continuum of Self-Managing Team Development," in Advances in Interdisciplinary Studies of Work Teams. vol. 1997, M. M. Beyerlein and D. A. Johnson, Eds., ed Stamford, Conn: JAI Press, 1997. 